\title{
In reply: Why remifentanil?
}

\author{
Wataru Sakai $^{1} \cdot$ Yusuke Yoshikawa $^{1} \cdot$ Michiaki Yamakage $^{1}$
}

Received: 6 March 2018 / Accepted: 18 March 2018 / Published online: 3 April 2018

(c) Japanese Society of Anesthesiologists 2018

To the Editor:

We wish to thank Dr. Lema $\mathrm{G}$ for his comments on our article [1].

Based on the anti-inflammatory and sympathoinhibitory effects of remifentanil, we considered that remifentanil might have a renal protective effect against acute kidney injury (AKI) after cardiac surgery with cardiopulmonary bypass (CPB). Additionally, a recent article showed that remifentanil had a renal protective effect against ischemicreperfusion injury in rat experimental models [2]. However, our results were not able to reveal that. One possible reason is that the amount of remifentanil administered in our cohort was not enough. Since the association between dose of remifentanil and AKI has not been evaluated yet, further studies will be required.

As Dr. Lema G mentioned, most of the patients in our study had almost normal renal function. A retrospective study showed the possibility that remifentanil could improve renal function of patients with chronic kidney disease (CKD) temporarily after general surgery [3]. If the renoprotective effect of remifentanil had been investigated in patients with $\mathrm{CKD}$, the results might have been different.

Acknowledgements We are indebted to Naoyuki Hirata M.D., Ph.D. for critical reading of this manuscript.

\section{Compliance with ethical standards}

Conflict of interest The authors declare that they have interest and nothing to disclose.

\section{References}

1. Sakai W, Yoshikawa Y, Hirata N, Yamakage M. Effect of remifentanil during cardiopulmonary bypass on incidence of acute kidney injury after cardiac surgery. J Anesth. 2017;31:895-902.

2. Erkilic E, Kesimci E, Alaybeyoğlu F, Kılınç I, Tural R, Yazgan A, Gümüş T, Sepici Dinçel A, Dumlu EG, Kanbak O. Does remifentanil attenuate renal ischemia-reperfusion injury better than dexmedetomidine in rat kidney? Drug Des Devel Ther. 2017;11(8):677-83.

3. Terashi T, Takehara A, Kuniyoshi T, Matsunaga A, Kawasaki K, Kanmura Y. Remifenitanil temporarily improves renal function in adult patients with chronic kidney disease undergoing orthopedic surgery. J Anesth. 2013;27:340-5.

This reply refers to the comment available at https://doi. org/10.1007/s00540-018-2488-6.

Wataru Sakai

sakaiwataru1128@gmail.com

Yusuke Yoshikawa

yusuke_19_@hotmail.com

Michiaki Yamakage

michiaki_yamakage@icloud.com

1 Department of Anesthesiology, Sapporo Medical University School of Medicine, West 16, South 1, Chuouku, Sapporo, Hokkaido 060-8556, Japan 